\title{
Climate change and predicted trend of fungal keratitis in Egypt
}

A. Saad-Hussein, ${ }^{1}$ H.M. El-Mofty ${ }^{2}$ and M.A. Hassanien ${ }^{3}$

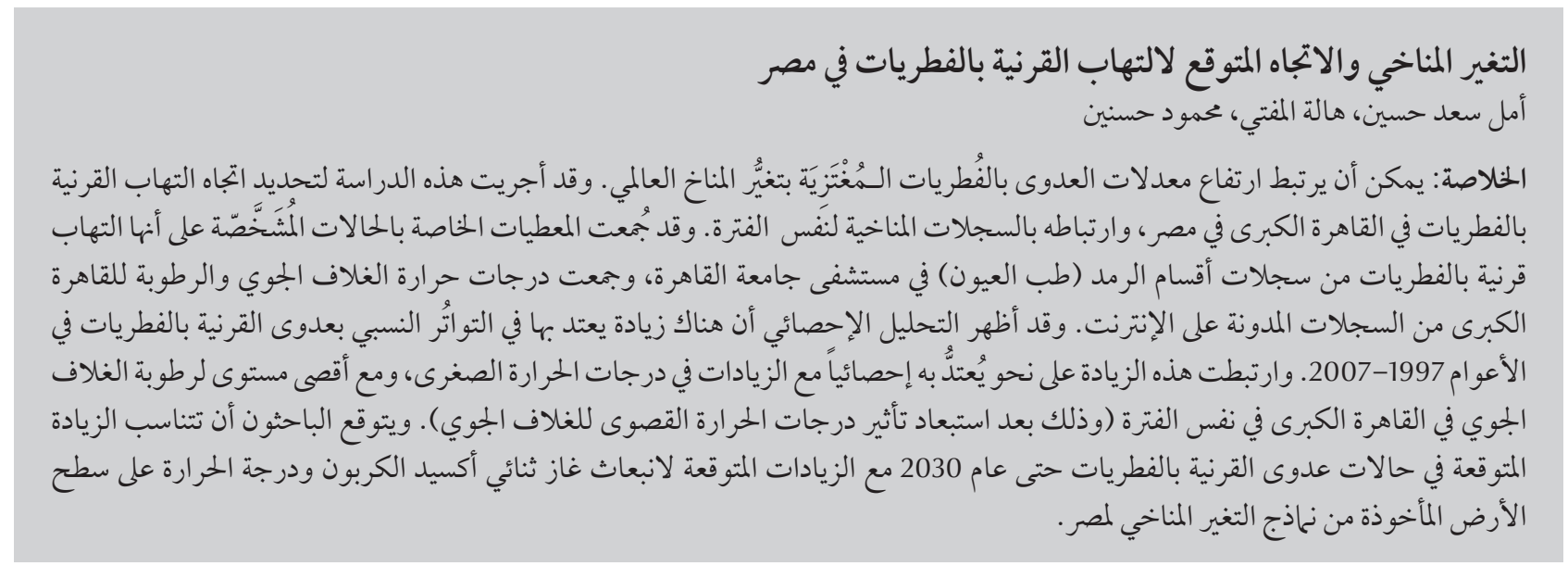

ABSTRACT Rising rates of invasive fungal infections may be linked to global climate change. A study was made of the trend of ophthalmic fungal corneal keratitis in the greater Cairo area of Egypt and its association with climate records during the same period. Data on diagnosed cases of fungal keratitis were collected from records of ophthalmic departments of Cairo University hospital and atmospheric temperature and humidity for the greater Cairo area were obtained from online records. Statistical analysis showed a significant increase in the relative frequency of keratomycosis during 1997-2007. The rise correlated significantly with rises in minimum temperature and the maximum atmospheric humidity in the greater Cairo area over the same period (after exclusion of the effect of the maximum atmospheric temperature). The predicted increase in keratomycosis up to the year 2030 corresponds to predicted increases in $\mathrm{CO}_{2}$ emissions and surface temperature from climate change models for Egypt.

\section{Changement climatique et prévision des tendances pour la kératite mycosique en Égypte}

RÉSUMÉ Les taux croissants des mycoses invasives pourraient être liés au changement climatique dans le monde. Une étude a été réalisée sur la tendance des kératites mycosiques dans le Grand Caire (Égypte) et sur son association avec les relevés des données climatologiques pendant la même période. Les données provenant des cas diagnostiqués de kératite mycosique ont été recueillies à partir des dossiers médicaux des services d'ophtalmologie de l'hôpital universitaire du Caire, alors que la température atmosphérique et les taux d'humidité pour le Grand Caire ont été obtenus à partir des archives en ligne. Une analyse statistique a révélé une augmentation significative de la fréquence relative des cas de kératomycose entre 1997 et 2007. Cette augmentation était fortement corrélée aux élévations de la température et au taux maximum d'humidité atmosphérique dans le Grand Caire pendant la même période (après avoir exclu l'effet de la température atmosphérique maximale). Les prévisions d'une augmentation des cas de kératomycose jusqu'en 2030 correspondent aux prévisions d'élévation des émissions de $\mathrm{CO}_{2}$ et de la température en surface selon les modèles de prévision du changement climatique pour l'Égypte. 


\section{Introduction}

Recent increases in the average temperature of the atmosphere near the earth's surface and in the troposphere are believed to contribute to changes in global climate patterns [1-4]. The warming that may be occurring as a result of increased emissions of greenhouse gases from human activities [1] is predicted to increase the average surface temperature of the earth by $1.4^{\circ} \mathrm{C}$ to $5.8^{\circ} \mathrm{C}$ by the end of the 21 st century relative to 1990 [2]. It is widely recognized that climate change, by altering local weather patterns and by disturbing the ecology of regions, has significant implications for human health [5]. Secondary health effects of climate change have already been observed, including bacterial and fungal proliferation [6]. A longitudinal dermatological study in The Gambia was carried out to determine the effect of seasonal change on the prevalence of fungal skin infection. The greatest effect of climatic change was on the prevalence of dermatomycoses in children under 10 years old [6].

Fungal keratitis (keratomycosis) is a major causes of infectious keratitis in tropical parts of the world [7]. Corneal ulcer has been called the silent epidemic cause of corneal blindness in the developing world. Every year in the developing countries, there are 1.5 to 2 million new cases, with a high frequency of fungal disease [8]. Because of the potential for permanent impairment of vision or perforation of the eye, corneal ulcer is considered an ophthalmic emergency.

In Egypt, the relatively high incidence of keratomycosis is due to the agricultural environment and a temperature which favours the abundance of fungi; misdiagnosis or delayed presentation aggravate the problem [9]. During the last 10 years an increase has been observed in the number of fungal corneal infection cases in outpatient clinics as well as inpatients of general ophthalmic hospitals in Egypt (El-Mofety, unpublished data). Using a local modification of the Regional Air Pollution Information and Simulation (RAINS) model, Hassanien has shown increases in $\mathrm{CO}_{2}$ emissions over the same period in Egypt, which are predicted to rise up the year 2030 [10] (Figure 1). Projected increases in annual temperature in Egypt using the General Circulation Model are $1{ }^{\circ} \mathrm{C}$ [standard deviation (SD) $0.15^{\circ} \mathrm{C}$ ] by the year 2030 and $1.4^{\circ} \mathrm{C}\left(\operatorname{SD~} 0.22^{\circ} \mathrm{C}\right)$ by 2050 [11].

The aim of the current study was to study the trend of ophthalmic fungal corneal keratitis in the greater Cairo area of Egypt over the period 1997-2007 to evaluate its association with temperature and humidity during this period and to predict the future trend up to the year 2030.

\section{Methods}

\section{Climate study}

Climate data in the form of annual average, maximum and minimum temperature and humidity records for Cairo, Egypt during the period of the study (1997-2007) were extracted from the website: http://arabic.wunderground. com/global/stations/62366.html. The data for this period was confirmed from the records of the Egyptian Meteorological Authority and from 1997 by the weather instruments of the Department of Air Pollution at the National Research Centre.

\section{Ophthalmic study}

The clinical study was conducted in Cairo University hospitals. All patients admitted to the hospital during the period of the study with clinical signs of fungal keratitis or corneal abscess that proved to be fungal by laboratory investigation (culture and sensitivity) were selected. The exclusion criteria were patients with a non-infective keratitis, e.g. autoimmune ulcers or other causes of infectious keratitis. Outpatients were not included. All the participants were asked to complete a medical history questionnaire to exclude a history of ocular trauma or contact lens wear.

Full ophthalmologic examination was done for all the included patients. The assessment included visual acuity,

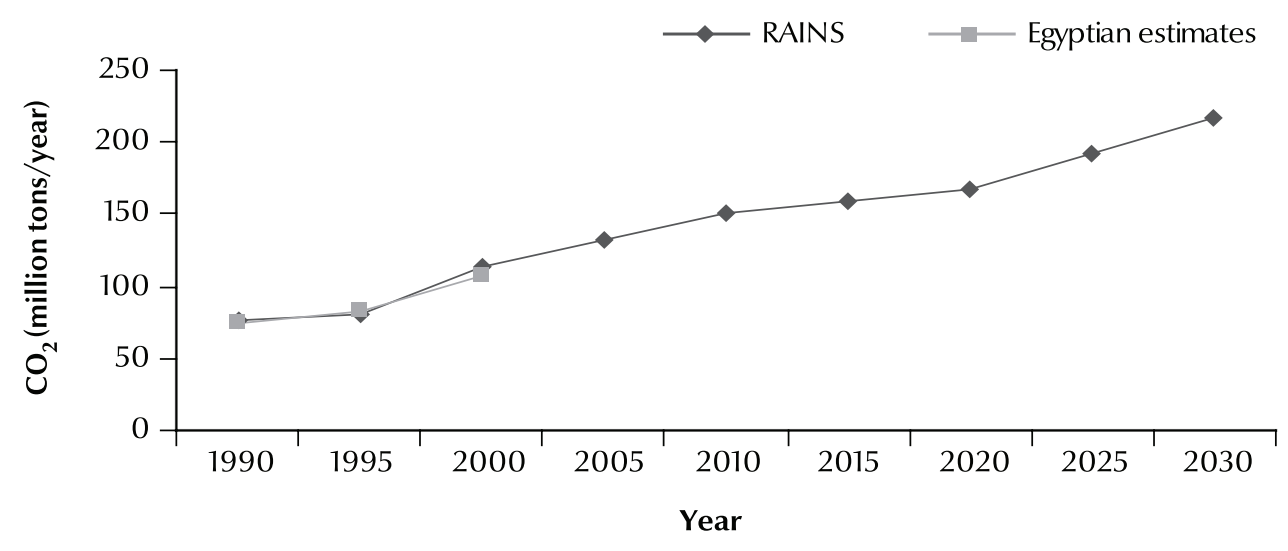

Figure 1 Predicted emissions of carbon dioxide $\left(\mathrm{CO}_{2}\right)$ in Egypt 1990-2030 and data from the Regional Air Pollution Information and Simulation (RAINS) model. Source: Hassanien [10] 
slitlamp examination to evaluate the extent and depth of the corneal ulcer and or abscess and the clinical characteristics of the lesion. Evaluation of the anterior segment including the anterior chamber of the eye for presence of hypopyon with iritis was also done. Special investigations were carried out by ultrasound to evaluate the posterior segment if it could not be seen by ophthalmoscope. Culture and sensitivity were done to identify the infecting organism if possible.

\section{Statistical analysis}

The data were revised and filtered; all patients with incomplete records or not fully diagnosed were excluded from the final statistical analysis. Relative frequency $(\mathrm{RF})$ of the recorded fungal infected cases to total recorded ophthalmic cases admitted to the ophthalmic department, regardless of cause of admission, was calculated as a percentage for each year. Statistical analysis of the collected data was done using SPSS, version 14.0. Pearson correlation coefficient, backwards and stepwise linear regression models were used. The significance level was considered at $P$-value $<0.05$.

\section{Results}

Figure 2a illustrates the linear regression of the RF of fungal keratitis with time during the period of the study (1997-2007). The RF of fungal keratitis increased steadily from $2.5 \%$ in 1997 to $6.2 \%$ in 2007 . The $R^{2}$ value (0.72) showed a positive linear relationship between RF and time in years $(P<0.001)$. The rates of each of the 2 forms of fungal keratitis were also significantly positive correlated with time: $r=0.90$ for abscess and $r=0.48$ for ulcer (Figure 2b).

Table 1 illustrates the backward linear regression model between the RF of fungal keratitis and time over the study period 1997-2007 and the temperature and humidity.Model 1 showed that there were significant relationships between
RF and both time and minimum atmospheric temperature throughout the period of the study. Model 2, after exclusion of the effect of the maximum atmospheric temperature, showed significant relationships between RF and time, minimum temperature and maximum atmospheric humidity.

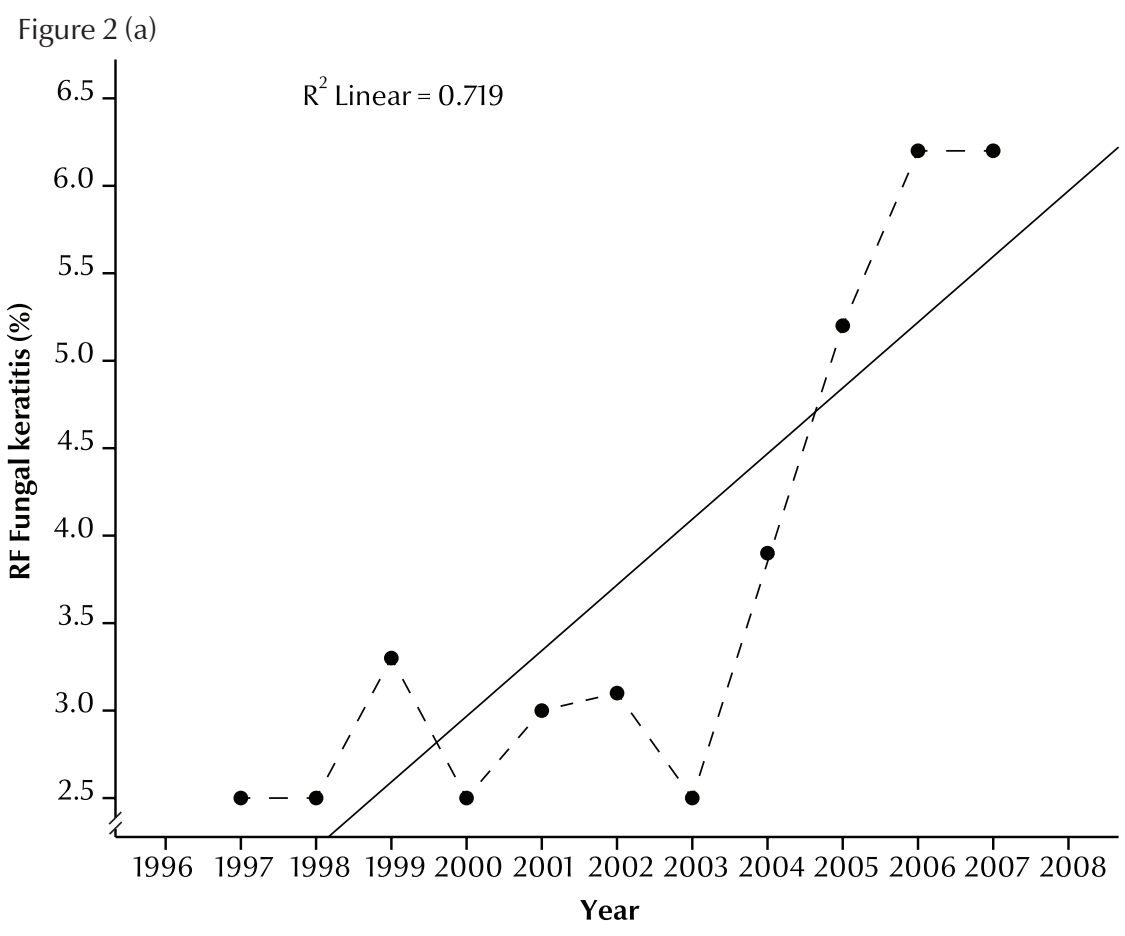

Figure $2(b)$

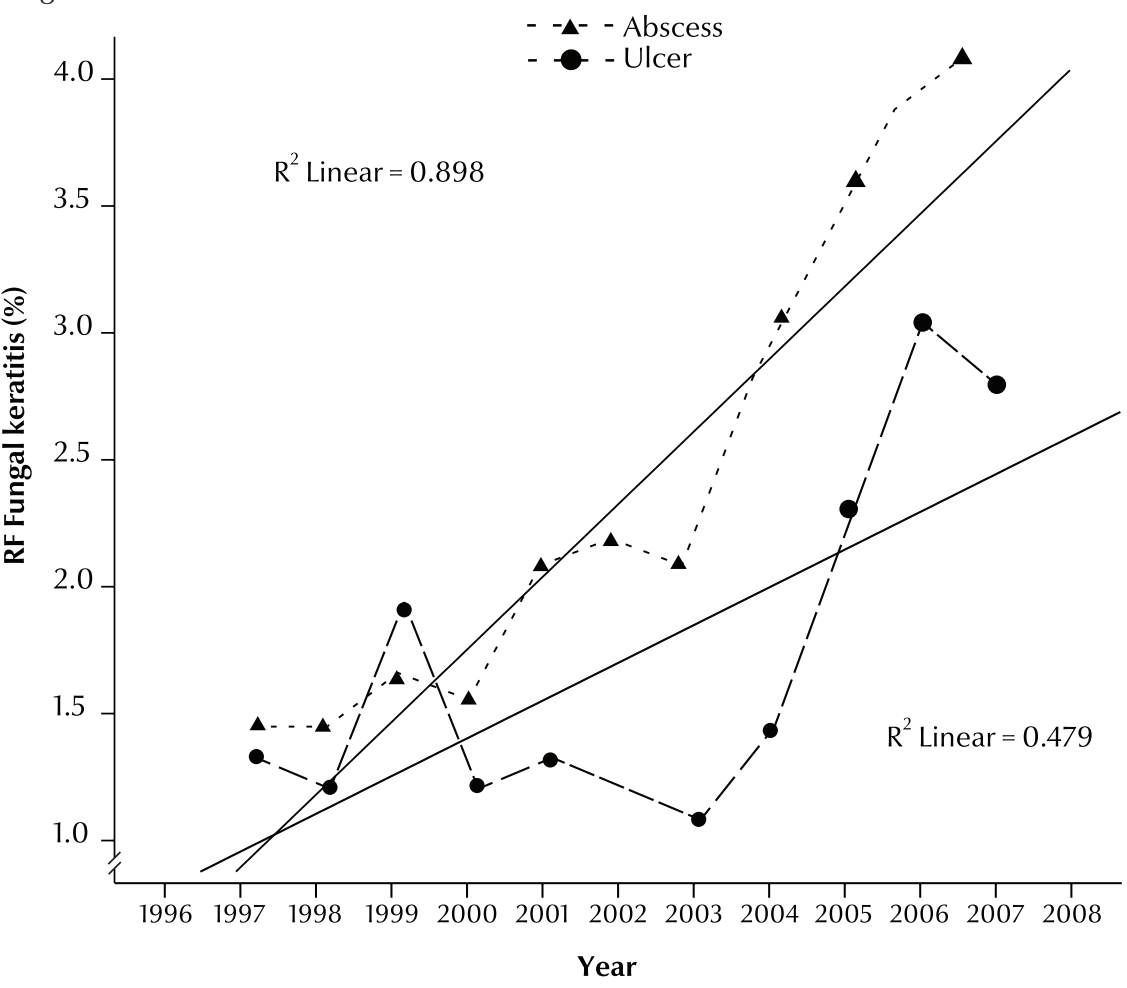

Figure 2 Trend of relative frequency (RF) of diagnosed cases of fungal abscess and ulcer in Egypt during 1997-2007: (a) for all cases; (b) for abscesses and ulcers 


\begin{tabular}{|c|c|c|c|}
\hline Coefficient model & $\begin{array}{l}\text { Standardized } \\
\text { beta coefficient }\end{array}$ & $t$-value & $P$-value \\
\hline \multicolumn{4}{|l|}{ Model 1} \\
\hline Years & 0.86 & 3.593 & 0.016 \\
\hline Temperature (maximum) & 0.22 & 0.769 & 0.477 \\
\hline Temperature (minimum) & 1.15 & 2.684 & 0.044 \\
\hline Humidity (maximum) & -0.62 & -2.064 & 0.094 \\
\hline Humidity (minimum) & 0.67 & 1.785 & 0.134 \\
\hline \multicolumn{4}{|l|}{ Model $2^{a}$} \\
\hline Years & 0.71 & 5.144 & 0.003 \\
\hline Temperature (minimum) & 0.90 & 3.339 & 0.002 \\
\hline Humidity (maximum) & -0.44 & -2.484 & 0.016 \\
\hline Humidity (minimum) & 0.44 & 1.977 & 0.095 \\
\hline
\end{tabular}

${ }^{a}$ Excluding the effect of the maximum atmospheric temperature. $N S=$ not significant.

For prediction of the trend of RF of fungal keratitis, stepwise linear regression was done to exclude the confounding effects of atmospheric temperature and humidity (Table 2). The standardized beta coefficient of the relation between the RF of fungal keratitis with the years was 0.38 after exclusion of the maximum and minimum temperature and the maximum and minimum humidity from the relationship.

Figure 3 also shows a significant increase in the predicted RF of fungal keratitis in the greater Cairo area up to the year 2030. The rate is predicted to rise from $6.7 \%$ in 2010 to $12.4 \%$ by the year 2025 and $14.2 \%$ by the year 2030 .

\section{Discussion}

Scarring of the cornea as a result of suppurative keratitis is an important preventable cause of blindness. In some developing countries, corneal infections are the second commonest cause of blindness after unoperated cataract [12]. Ulcerative keratitis due to infection with a wide range of organisms has been reported, e.g. viruses, bacteria, fungi or protozoa. There are also regional variations in the predominance of different microbes, reflecting different patient populations and climate effects. In tropical regions of the world fungal keratitis is a common and important cause of corneal morbidity [13].

The present results revealed that the RF of fungal corneal infection a referral hospital in Cairo increased significantly during the 10-year period of the study (1997-2007). This increase in RF of fungal keratitis was significantly correlated with the increase in the average atmospheric minimum temperature in the same area (greater Cairo) over the same period, but was significantly inversely correlated with maximum humidity throughout the study period. The rate of fungal abscess seemed to be increasing at a faster rate than the ulcer forms of keratitis. However, our study recorded inpatient cases only and corneal abscesses cases are more likely to be admitted for fear of globe perforation or endophthalmitis. Corneal ulcers cases are more likely to be managed on an outpatient basis, unless the patient is monocular or referred from a geographically distant centre or if a complicated ulcer is present.

Our results agree with the results of Baharathi et al., who evaluated the influence of climate and geographical variations in microbial keratitis in south India [13]. Their retrospective study of clinically diagnosed microbial keratitis evaluated a total of 3183 cases, $34.4 \%$ of which proved to be of fungal origin. The incidence of fungal keratitis was higher between June and September. They concluded that a hot and windy climate makes fungal keratitis more frequent in tropical zones [13]. The results of our study were also similar to study in Nigeria, which experiences a climate similar to that of South India. They reported a higher incidence of fungal keratitis during hot and humid seasons [14]. Also, in Hyderabad, India, Gopinathan et al. concluded that fungal keratitis was more frequent due to the hot and humid windy climate in this tropical zone and the agriculture-based occupation of the population [15].

We suggest that due to the increasing the population in Egypt and the rising RF of fungal keratitis found in the present study, fungal infections will become an increasing health problem in the country. Heightened awareness of the problem among ophthalmologists

\begin{tabular}{lccc}
\hline $\begin{array}{l}\text { Table } 2 \text { Stepwise linear regression of relative frequency } \\
\text { time after exclusion of confounding effects of atmospheric temperature }\end{array}$ & and humidity \\
\hline Coefficient model & $\begin{array}{c}\text { Standardized beta } \\
\text { coefficient }\end{array}$ & $\boldsymbol{t}$-value & \multicolumn{1}{c}{$\boldsymbol{P}$-value } \\
Constant & -747.942 & -4.779 & $<0.001$ \\
Years & 0.38 & 4.803 & $<0.001$ \\
Excluded variables & & & \\
$\quad$ Temperature (maximum) & -0.22 & -0.976 & 0.358 \\
Temperature (minimum) & -0.32 & -1.855 & 0.101 \\
Humidity (maximum) & -0.01 & -0.047 & 0.964 \\
Humidity (minimum) & -0.15 & -0.736 & 0.483 \\
\hline
\end{tabular}




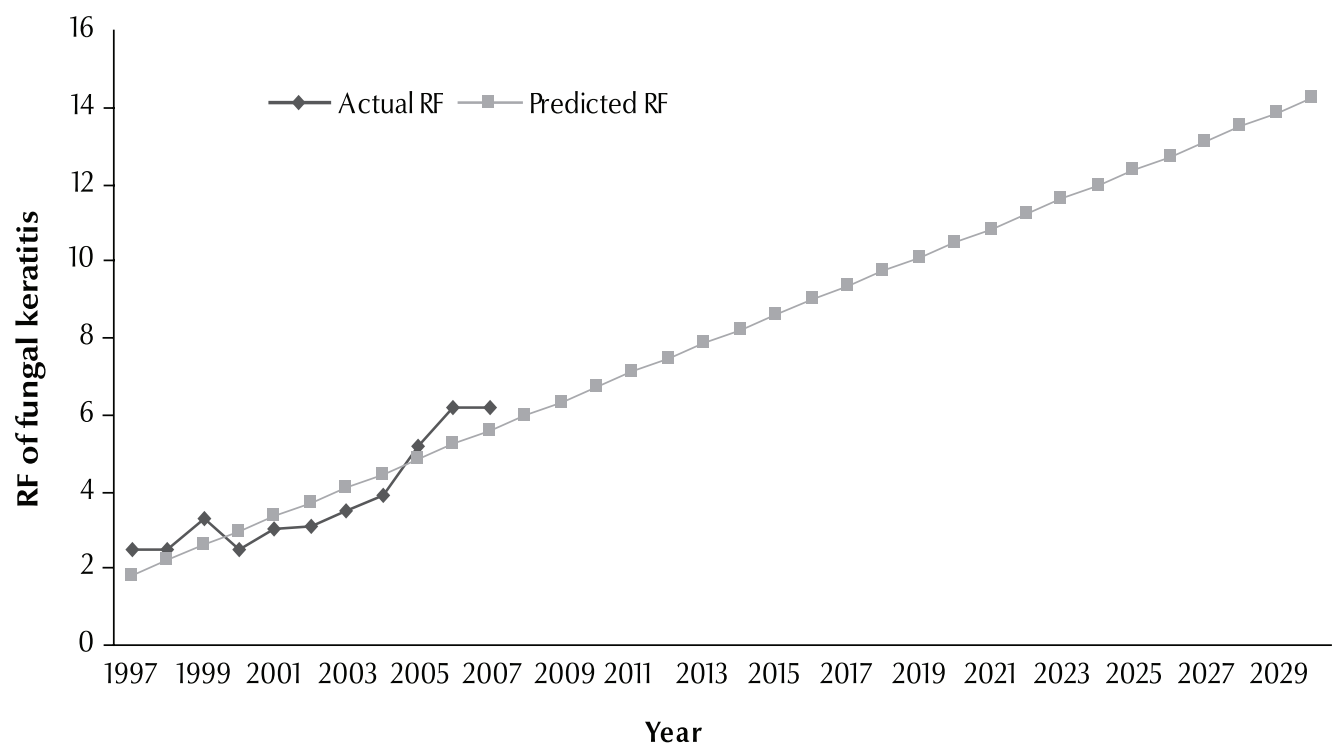

Figure 3 Predicted relative frequency (RF) of diagnosed cases of fungal keratitis in Egypt up to the year 2030

and medical microbiologists may have contributed to the increasing recognition of the disease [16]. Fungal infections are a major problem for immunocompromised persons, including HIV patients and people receiving chemotherapy for cancer or patients treated with corticosteroids $[17,18]$. The climate changes noted here suggest that fungal growth may become more frequent in domestic and industrial buildings in Egypt, as indicated by increases in the RF of fungal keratitis in the present study and increases in the mould concentrations in the houses of asthmatic children in Cairo [SaadHussein. unpublished data]. Mycotoxins may act as immunosuppressants and may be associated with an increase in the prevalence of repeated infections among the inhabitants of buildings with moisture problems $[19,20]$.

Whether fungal infection is acquired through contaminated water or through airborne spores is a matter of much debate [21]. Bioaerosols are defined as airborne particles consisting of microorganisms (bacteria, viruses, moulds) or metabolites, toxins or fragments from microorganisms. In conditions of higher humidity, higher bioaerosol levels can prevail. Airborne fungal cells can remain viable for much longer periods, even at low relative humidity and high or low temperature extremes. The extent of the transport of airborne particulate depends on the surface temperature, air temperature, and wind speed, all of which are predicted to change as a result of climate change [21]. Several studies have shown that under drier conditions, bioaerosols such as fungal spores and endotoxins are likely to be more problematic [22]. This explains our results, as after excluding the confounding impact of the atmospheric maximum temperature, the significant increase in the RF of fungal infections was shown to be significantly related to the increase in the atmospheric minimum temperature and to the decrease in the maximum humidity. On application of a stepwise linear regression model in the current study, the RF of fungal keratitis was predicted to double from $6.2 \%$ in the year 2007 to $12.4 \%$ in the year 2025 . By the year 2030, it was expected to be $14.2 \%$.
There are some limitations to our study. Although it was conducted in one of the largest referral hospitals in Cairo, our sample represented only a small proportion of the Egyptian population and the rate of fungal corneal infection recorded may therefore be over- or underestimated. Thus, we used the RF of fungal corneal infections as a proxy for the incidence of infections. We also ensured that the recorded atmospheric temperature and humidity during the period of study covered only the same area of Greater Cairo.

In conclusion, climate change cannot be neglected as a potential risk factor for the increase in the RF of fungal keratitis in our referral hospital during the period of this study. Further largescale and national studies to find out the actual incidence of the problem in Egypt and correlate it with climate changes are recommended. Enhanced surveillance and reporting of fungal keratitis will be critical to improve our understanding of the importance of invasive fungal infections, to enable prioritization of research and prevention efforts and to evaluate prevention strategies. 


\section{References}

1. Houghton JT, Callander BA, Varney SK, eds. Intergovernmental Panel on Climate Change. Climate change 1992. The supplementary report to the IPCC scientific assessment. Cambridge, Cambridge University Press, 1992.

2. National Research Council. Climate change science: an analysis of some key questions. Washington DC, National Academy Press, 2001.

3. National Research Council. Surface temperature reconstructions for the last 2000 years. Washington DC, National Academy Press, 2006.

4. Temperature trends in the lower atmosphere: steps for understanding and reconciling differences. A report by the Climate Change Science Program and the Subcommittee on Global Change Research. Washington DC, Intergovernmental Panel on Climate Change, 2006.

5. Ezzati $\mathrm{M}$ et al.; Comparative Risk Assessment Collaborating Group. Selected major risk factors and global and regional burden of disease. Lancet, 2002, 360:1347-1360.

6. Porter MJ. Seasonal change and its effect on the prevalence of infectious skin disease in a Gambian village. Transactions of the Royal Society of Tropical Medicine and Hygiene, 1980, 74:162-168.

7. Agrawal $\vee$ et al. Current perspectives in infectious keratitis. Indian Journal of Ophthalmology, 1994, 42:171-192.

8. Whitcher JP, Srinivasan M. Corneal ulceration in the developing world-a silent epidemic. British Journal of Ophthalmology, 1997, 81:622-623.

9. Al-Hussaini AK, El-Said I, El-Shanwany AR. Topical clotrimazole for the treatment of fungal keratitis in humans. Bulletin of the Ophthalmological Society of Egypt, 1997, 90:813.

10. Hassanien MA. An initial implementation of the RAINS model to assess emission of air pollutants in Egypt. Interim report IR-03045. Laxenburg, Austria, International Institute for Applied Systems Analysis, 2003.
11. Agrawala $\mathrm{S}$ et al. Development and climate change in Egypt: focus on coastal resources and the Nile. Paris, Organisation for Economic Co-operation and Development, 2004.

12. Leck AK et al. Aetiology of suppurative corneal ulcers in Ghana and south India, and epidemiology of fungal keratitis. British Journal of Ophthalmology, 2002, 86:1211-1215.

13. Bharathi MJ et al. Microbial keratitis in South India: influence of risk factors, climate, and geographical variation. Ophthalmic Epidemiology, 2007, 14:61-69.

14. Gugani HC, Tawlar RS, Njoku OBI. Mycotic keratitis in Nigeria. A study of 21cases. British Journal of Ophthalmology, 1995, 79:1024-1028.

15. Gopinathan $U$ et al. The epidemiological features and laboratory results of fungal keratitis: a 10-year review at a referral eye care center in South India. Cornea, 2002, 21:555-559.

16. Anuradha C, Kirti S. Spectrum of fungal keratitis in north India. Cornea, 2005, 24(1):8-15

17. Mahoney DP, Spear JE. Health hazards of mold: risk assessment and remediation. Personal safety. Des Plaines, Illinois, American Society of Safety Engineers, 2003.

18. Warnock DW. Trends in the epidemiology of invasive fungal infections. Nippon Ishinkin Gakkai Zasshi, 2007, 48:1-12.

19. Leino $\mathrm{M}$ et al. Intranasal exposure to a damp building mould, Stachybotrys chartarum, induces lung inflammation in mice by satratoxin-independent mechanisms. Clinical and Experimental Allergy, 2003, 33:1603-1610.

20. Reijula K, Tuomi T. Mycotoxins of aspergilli: exposure and health effects. Frontiers in Bioscience, 2003, 8:s232-s235.

21. Boxall ABA et al. Impacts of climate change on indirect human exposure to pathogens and chemicals from agriculture. Environmental Health Perspectives, 2009, 117:508-514.

22. Pillai SD, Ricke SC. Bioaerosols from municipal and animal wastes: background and contemporary issues. Canadian Journal of Microbiology, 2002, 48:681-696. 